\title{
Effect of Nursing Management Protocol On luds Performance
}

\author{
Iman Rashad*, Sahar Naguib Mohammed*, Shadia Abdel Qader Hassan, ${ }^{\dagger}$, Maher Salah

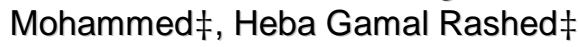

\begin{abstract}
Background: Intrauterine Devices (IUDs) remain an attractive birth-control option for many women who desire a highly effective form of birth control but cannot tolerate or do not want to use hormonal implants. However, fears about side effects, concerns about infection and infertility, lack of technical training for providers, and the time and costs involved in providing services combine to discourage their use. Objective: to assess the magnitude and types of problems associated with use of IUDS, and to examine the effect of a plan of nursing intervention on the performance of IUDs. Methods: The study was conducted in the Family planning outpatient clinic of Assiut University Hospital. A cross-sectional descriptive design, and a quasi-experimental research design with pre-post assessment were used. The assessment sample consisted of 409 women. The intervention group included 100 new IUD users who were randomly allocated into two equal groups of 50 women each. Subgroup A women received the intervention program without provision of prophylactic antibiotics, while subgroup B women received the program in addition to prophylactic antibiotics. The tools used for data collection were a structured interviewing questionnaire sheet for both the assessment and the intervention groups, and an examination form to record the clinical and laboratory findings of the intervention group. A follow-up sheet was used to record any possible complications one month after insertion. A pre-post-FU questionnaire form was used to assess women's knowledge and misconceptions before and after the intervention. The study started at the beginning of April 2002 and ended in October 2003. Results: Only $17.6 \%$ of the women have reported no complications related to use of contraceptives. Vaginal bleeding and infection were the most common complications, $14.4 \%$ and $10.5 \%$, respectively. The most common infection was Chlamydia (20.6\%). Subgroup A women (no-prophylactic antibiotic) had a higher incidence of erythema and vaginal discharge at the follow-up vaginal examination, compared to pre-program rate, $34.0 \%$ and $10.0 \%$, respectively $(p=0.004)$. Also, women in subgroup $A$ had a higher incidence of bacterial vaginosis (16.0\%), compared those in subgroup $B$ (4.0\%), $p=0.046$. In subgroup $B$, positive chlamydial infection decreased from $34.0 \%$ at the pre-program exam to $10.0 \%$ at the FU $(p<0.001)$, and other bacterial infections from $28.0 \%$ to $12.0 \%$ at the $F U(p=0.046)$. Statistically significant improvements in correct knowledge and misconceptions were revealed in all areas at the post-test and FU, $p<0.001$. Conclusion and Recommendations: bleeding, infection, and dyspareunia were the most commonly reported problems among IUD users. Women had poor knowledge and many misconceptions about IUDs. The planned nursing intervention succeeded in improving their knowledge and correcting their misconceptions. Prophylactic antibiotics were also effective in reducing infections. Therefore, it is recommended to apply this intervention on a wider scale.
\end{abstract}

\section{INTRODUCTION}

Worldwide, nearly 160 million women use Intrauterine Devices (IUDs). The popularity of intrauterine devices stems for their effectiveness, combined with their long duration of action. It remains an attractive birth-control option for many women who desire a highly effective form of birth control but cannot tolerate or do not want to use

\footnotetext{
* Faculty of Nursing, Asuit University

+ Faculty of Nursing, Cairo University

‡ Faculty of Medicine, Asuit University
} 
hormonal implants, women who cannot see a physician frequently for refills of contraceptive prescriptions, women who cannot use contraceptive methods at the time of intercourse, and women who require an inexpensive method of birth control that requires no intervention at the time of intercourse (Gareen, 2003) ${ }^{1}$.

Nevertheless, the full range of modern family planning methods still remains unavailable to at least 350 million couples worldwide, many of whom wish to space or prevent another pregnancy, despite their individual right to the benefits of scientific progress (WHO, 2004) $)^{2}$. In Egypt, it is the most popular method of contraception. It has a long-term effect and is the least expensive method to use (Shaaban, 2002) ${ }^{3}$.

Insertion of IUD is considered a risk factor for acquiring pelvic inflammatory disease (PID). However, IUDs by themselves do not cause PID, and for most IUD users, fertility returns quickly after the device is removed. When IUDs are inserted in candidates who are at low risk for STDs, PID rarely occurs (Kaunitz, 1999) ${ }^{4}$. Moreover, the association between IUD use and PID has been attributed to factors other than the IUD (Gareen, 2003) ${ }^{1}$. The risk is increased in the three weeks following insertion, particularly in those at risk of sexually transmitted infections (MMWR, 2002) ${ }^{5}$. Also, IUD use may carry some risk of infection for some women, primarily due to non-sterile insertion technique (Barnett, 2000) $)^{6}$.

However, fears about side effects, concerns about infection and infertility, lack of technical training for providers, and the time and costs involved in providing services combine to discourage use of IUDs in some countries (Walsh et al., 1998)7. Additionally, an international mail survey conducted by the International Planned Parenthood Federation (IPPF) and the World Health Organization (WHO) has revealed that inaccurate information about IUDs is a barrier to use worldwide. Therefore, IUDs will continue to be underutilized in many countries until health 
workers are trained in three essential aspects of IUD use, namely the latest scientific information on the device, proper insertion method, and good counseling techniques (Barnett, 2000)6; Brambila and Taracena, 20038; Gyapong et al., 20039).

Modern IUDs are safer than ever before, and women without cervical infections have the lowest risk of upper-genital-tract infections related to IUD use (David, 2000) ${ }^{10}$. The copper $\mathrm{T}$ intrauterine device is the most popular. It is safe and reversible, requires little effort on the part of the user once inserted, and offers 10 years of prevention against pregnancy (Barnett, 2000) ${ }^{6}$. Also, in copperreleasing IUDs, there is a lower risk of ectopic pregnancy (Steiner, 1999) ${ }^{11}$. Therefore, women must be fully informed about the IUD before choosing it, and health care workers must be adequately trained to insert the device, if the IUD is to be used properly (Finger, 2002) ${ }^{12}$.

The influence of IUD use on the occurrence of vaginal flora changes and bacterial vaginosis remains a controversial issue (Harikarnpukdee et al., 2004) ${ }^{13}$. Meanwhile, women with symptomless gonorrhea or chlamydial infection with an IUD have a higher risk of salpingitis and tubal infertility (David, 2000'10; Grimes, 2000) ${ }^{14}$. Raising consciousness about the gravity of the problem, on the one hand, and its simple, inexpensive solution, on the other, is essential. This might be achieved through making consumers and purchasers of health care increasingly aware of the medical, psychosocial, and economic burdens of chlamydia, as well as the increased ease and low cost of screening and treatment (Coffield et al., 2001) ${ }^{15}$. This is of special importance given that uncomplicated chlamydial infection of the lower genital tract is simple to detect and treat (Teran et al., 2001'16; Walsh and Irwin, 2002 ${ }^{17}$ ).

Recently, interest has grown in the use of prophylactic antibiotics at the time of IUD insertion to decrease the risk of infection (Grimes and Schulz, 200018). There is a 
theoretical rationale for this practice, as PID rates in IUD users are highest in the first few weeks, and antibiotics could reduce these rates. Nevertheless, there is a paucity of research in this area, and there is even some debate, since the Population Information Program (1996) ${ }^{19}$ found a lower rate of PID with prophylactic antibiotics, whereas Timothy and Canavan (1998) ${ }^{20}$ failed to show any difference. In addition, there is some concern about the programmatic feasibility and cost of prophylactic antibiotics (Population Information Program, 1996) ${ }^{19}$.

Additionally, Post-insertion counseling is usually given immediately after IUD insertion, but some information should be given earlier and then reinforced after insertion. In particular, information of follow-up and on warning signs that necessitate a quick return to the clinic must be provided (WHO, 1997) ${ }^{21}$. A well-informed patient is more likely to continue with IUDs method and less likely to request premature removal. Programs may be able to tailor counseling to help their clients decide about IUD use, and to use IUDs with greater satisfaction (Timothy and Canavan, 1998) $)^{20}$.

\section{Aim of the study}

The aim of this study was to assess the magnitude and types of problems associated with use of IUDS, and to examine the effect of a plan of nursing intervention on the performance of IUDs.

\section{MATERIAL AND METHODS}

\section{Research design}

A cross-sectional descriptive design was used to achieve the first aim, and a quasiexperimental research design with pre-post assessment was utilized for the second aim of this study.

\section{Setting}

The study was conducted in the Family planning outpatient clinic of Assiut University Hospital, which provides family planning services for approximately 4000 women 
annually. The IUD sector represents $40 \%$ of the total cases.

\section{Study subjects}

The assessment sample consisted of all IUD users who attended the family planning outpatient clinic during the period from the beginning of April 2002 and ended in October 2003. The only inclusion criterion was a minimum of one-month use. Their total number was 409 women. The second group, intervention group, included 100 new IUD users who were randomly allocated into two equal groups of 50 women each. Subgroup A women received the intervention program without provision of prophylactic antibiotics, while subgroup B women received the program in addition to prophylactic antibiotics.

\section{Data collection tools}

The following tools were used for data collection:

\section{- Structured interviewing questionnaire}

sheet: designed by the investigators to collect women socio-demographic data as age, residence, educational level, religion, occupation, duration of marriage, and age at marriage. It also included questions about obstetric and contraception history such as parity, previous contraceptive methods, as well as the complications experienced during previous and/or current use. This sheet was used for both the assessment and the intervention groups.

- Examination form: designed by the investigators to record the findings of gynecological examination, which included bimanual and Cusco's speculum examination to assess the vaginal wall, vaginal discharge, and condition of the cervix, done under gynecologist supervision. It also served to record the results of laboratory investigations, which included vaginal swabs for bacterial vaginosis and other organisms $(G+v e$ cocci and G-ve bacilli) and endocervical swabs for detection of Chlamydia trachomatis. These were taken once from only 110 women in the assessment group, and twice for each 
woman in the study group: once at first visit, and the second at one-month follow-up.

- Follow-up sheet: designed for women in the study group to record any possible complications one month after insertion assessed through interviewing. The same clinical exam and laboratory investigations were repeated, in addition to checking for the IUD threads.

- Pre-post-FU questionnaire form: This form was designed to assess women's knowledge and misconceptions related to use of IUDs before and after the intervention. The knowledge part included questions related to genital organs, IUD shape, site of insertion, mechanism of action, who is responsible for its insertion, effectiveness, suitable time for insertion, schedule of visits and follow-up, indications, contraindications, advantages, disadvantages, ideal method to care, times of checking strings, when a copper IUD need to be replaced, and the warning signs. Misconceptions about IUD included travel to other parts of the body, entering in baby's body in case of pregnancy, preventing women from having babies after it is removed, rest period after using IUD for several years, severe bleeding, and affecting health and sexual life. The form was used before the program, immediately after, and the one-month follow-up visit.

\section{Procedures}

The investigators started by obtaining official permissions to conduct the study from the Directors of Assiut University Hospitals and of the Family planning outpatient clinic after explaining to them the nature and importance of the research. The tools for data collection were prepared based on review of related literature, and were validated through experts' opinions. Then, the study was carried out in two main phases, namely assessment and intervention.

Assessment phase: This involved both the assessment and intervention groups. Women

were approached by the investigators who explained to them the aim and procedures of 
the study, and asked for their verbal consent to participate. The investigators then interviewed women individually; each interview took 10-15 minutes. For women in the intervention group, the interview took 15-20 minutes to obtain detailed data about any contraindications for IUD insertion.

Following interviewing, each woman in both groups was subjected to a gynecological examination, including bimanual and Casco's speculum examination. In the intervention group, this examination also helped to exclude any possibility of PID or any adnexal masses, or any other gynecological problems that prevent IUD insertion. By the end of the examination, vaginal and endocervical swabs were taken if the woman was not menstruating, and then IUD was inserted under supervision of gynecologist. As for menstruating women, they were given another appointment for taking the swabs after the end of menstruation. The vaginal swabs were taken from vaginal discharge on vaginal mucosa and sent to the laboratory for staining.
The endocervical swabs were taken by special Dacron swab and sent to lab for detection of Chlamydia using Chlamyelia trachomatis antigen by HEXAGON Chlamydia kit provided by Human Diagnostic, Germany.

Intervention phase: After assessment and examination of women in the intervention group, the pre-test knowledge and misconceptions questionnaire was filled from them through interviewing. This was done by the outpatient clinic nurse to avoid any observer's bias. Then, women were randomly allocated to either subgroup A or subgroup B. Porphylactic antibiotics were provided to women in subgroup B only. Doxycycline 100 mg twice daily for five days was prescribed to non-lactating women, and Erythromycin 500 $\mathrm{mg}$, three times daily for five days for lactating women. All women in the two groups were given appointments for attending the intervention program.

Based on the data obtained from the filled knowledge and misconceptions questionnaire, the investigators developed a booklet - nursing 
management protocol - for improvement of women's knowledge, and correction of their misconceptions. It depended mainly on illustrations, models, and pictures as a large proportion of the women were illiterate. The booklet covered information about external and internal genital organs, shape of IUD and insertion technique, and its mechanism of action, indications, contraindications, advantages, side effects, the ideal method to care for IUD and times to feel threads with special position that make touch of threads more easier, schedule of visits, as well as scientific corrections for misconceptions.

The content of the booklet was reviewed with each individual woman after administration of the pre-test, and before the insertion of the IUD. After the insertion, the woman was given a clinic card for follow-up, in addition to the instructional booklet. An immediate post-test was done, and a follow-up visit was scheduled after one month.

At the follow-up visit, a posttest was done to measure the change in women's knowledge

and misconceptions. This was also done through interviewing by the outpatient clinic nurse to avoid any researchers bias. Then, woman was subjected to examination to ascertain the presence of the IUD in place, and to check for any infection through gynecological examination. The second vaginal and endocervical swabs were then taken and sent to the laboratory for analysis. The study started at the beginning of April 2002 and ended in October 2003.

Ethical considerations and human rights

The study subjects were informed about all the procedures and their informed consents were obtained. They had the choice to discontinue whenever they liked. Complete confidentiality and privacy were ensured. The intervention could not have any harmful effects on participants. Women were instructed about the results of their examinations and laboratory investigations, and were provided professional help when needed.

\section{Statistical analysis}


Data entry and analysis were done using SPSS 10.0 statistical software package. Data were presented using descriptive statistics in the form of frequencies and percentages for qualitative variables, and means and standard deviations for quatitative variables. Quantitative continuous data were compared using Student t-test. Qualitative variables were compared using chi-square test. Whenever the expected values in one or more of the cells in a $2 \times 2$ tables was less than 5 , Fisher exact test was used instead. In larger than $2 \times 2$ cross-tables, no test could be applied whenever the expected value in $10 \%$ or more of the cells was less than 5. Statistical significance was considered at $p$-value $<0.05$.

\section{RESULTS}

Table 1 describes the socio-demographic characteristics of women included in the assessment survey sample. Their mean $\pm S D$ age was $31.0 \pm 7.5$ years. About two-fifths of the women in the sample $(40.1 \%)$ were illiterate, and only about one-tenth had a university education. The majority were
Muslims (95.1\%), housewives (83.9\%), living in rural areas (74.6\%). The mean age at marriage was 19.0 years, and the mean duration of marriage was 11.1 years.

Concerning obstetric and contraception use data of the assessment group, Table 2 shows that the mean $\pm S D$ parity was $4.0 \pm 2.5$. Slightly more than two-thirds of the women in the sample $(68.0 \%)$ had a history of use of contraception, and less than two-fifths of them (38.9\%) had previously used IUDs. Only about less than one-fifth of the women (17.6\%) have reported no complications related to use of contraceptives. Vaginal bleeding and infection were the most common complications, $14.4 \%$ and $10.5 \%$, respectively. The rate of pregnancy with contraception use was $5.1 \%$. As regards changes in menstrual cycle, the most commonly reported was increased amount (38.1\%), whereas the least was spotting (5.9\%). About two-fifth of the women had dyspareunia (43.0\%). The most common infection was Chlamydia (20.6\%). 
Comparing the socio-demographic characteristics of women in the two intervention subgroups, table 3 indicates no statistically significant differences between them. Their mean ages were close. Less than one-third of the women in the two subgroups were illiterate. The majority were Muslims, and housewives. Slightly less than half of the women in subgroup A were living in rural areas $(44.0 \%)$, whereas slightly less than half of the women in subgroup B were living in urban areas (46.0\%), but the difference was not statistically significant. The mean age at marriage was about 20 years in both subgroups.

Table 4 shows that women in the two intervention subgroups had close parity. The history of previous use of contraception was statistically significantly higher in subgroup B, $\mathrm{p}=0.032$. About one-third of women in subgroup $A$, and about half of those in subgroup B gave a history of previous use of IUDs, but the difference was not statistically significant. The rates of no related complications in the two subgroups were $44.4 \%$ and $37.5 \%$, respectively. Vaginal bleeding was the most commonly reported complication in the two subgroups. However, amenorrhea was statistically significantly higher in subgroup A, compared to subgroup $B(p<0.001)$.

Comparison of the clinical local examination findings revealed no statistically significant differences among women in the two intervention subgroups, either preprogram or at follow-up (FU), table 5. The majority had normal vulva and cervix. Meanwhile, subgroup A women had a higher incidence of erythema and vaginal discharge at the follow-up vaginal examination, compared to pre-program rate, $34.0 \%$ and $10.0 \%$, respectively. This difference was statistically significant $(p=0.004)$.

Table 6 illustrates a comparison of the laboratory findings revealed among women in the two intervention subgroups. It points to only a statistically significant difference between the two subgroups at the follow-up as 
regards bacterial vaginosis $(p=0.046)$. It is evident that women in subgroup $A$ had a higher incidence of bacterial vaginosis (16.0\%), compared those in subgroup B (4.0\%). The table also shows statistically significant decreases in subgroup $B$ in the percentages of women with positive chlamydial infection, from $34.0 \%$ at the preprogram exam to $12.0 \%$ at the follow-up $(p<0.001)$. Similarly, the rates of other bacterial infections decreased in the same subgroup from a pre-program percentage of $28.0 \%$ to $12.0 \%$ at the follow-up $(p=0.046)$.

The results of assessment of women's knowledge in the intervention group throughout the study phases are presented in table 7. At the pre-program phase, the percentages of women having correct knowledge were very low. Thus, only $2.0 \%$ knew about the proper care for IUD, and $9.0 \%$ knew about the external genitalia. However, the majority had a correct knowledge about the person who is responsible for IUD insertion (84.0\%). Statistically significant improvements in correct knowledge were revealed in all areas at the post-test, reaching $100.0 \%$ for the knowledge about the person who is responsible for insertion, and the time of IUD replacement. Similar statistically significant improvements were revealed at the FU test, although some declines were noticed in some areas, and increases in other areas.

As regards the misconceptions related to IUDs among women in the intervention group, table 8 shows statistically significant improvements both at the post and follow-up phases $(p<0.001)$. At the pre-program phase, more than two-thirds of the women had the misconception that IUD can cause severe bleeding and affect health (72.0\%). This percentage declined to $30.0 \%$ and $31.0 \%$ at the post and follow-up phases, respectively. Similarly, slightly less than half of the women had the misconception that IUD can affect sexual desire (47.0\%). This percentage decreased to $10.0 \%$ and $6.0 \%$ at the post and follow-up phases, respectively. All these differences were statistically significant. 


\section{DISCUSSION}

The intrauterine device (IUD) is one of the most prevalent and effective reversible methods of contraception worldwide, and millions of IUDs are inserted yearly. However, it is used far less often than experts believe it should be used. Basically, this is believed to be the result of the concerns of clinicians for the risk of complications linked to its use, particularly PID and subsequent sequels (Hubacher et al., 2006) 22. The aim of the present study was to assess the magnitude and types of problems associated with use of IUDS, and to examine the effect of a plan of nursing intervention on the performance of IUDs.

The risk of PID prevents many from using IUDs. The present study revealed that less than one-fifth of the women in the assessment group have reported no complications related to use of contraceptives. Reproductive trat infection (RTI) was one of the most common complications, as reported by $10.5 \%$ of the women. The most common infection was chlamydia (20.6\%). These figures are slightly lower compared to those reported by Faúndes et al., (1998) ${ }^{23}$ where $35 \%$ of IUD users had RTIs, and the incidence of chlamydial infection was $7 \%$. The figures are also much less than those of Bogavac et al., (2004) $)^{24}$ in Yugoslavia, where the incidence of chlamydial infection associated with IUD was $41.7 \%$. On the contrary, Avonts et al., (2005) ${ }^{25}$ found a lower incidence cervical chlamydial infection in among IUD users (0.8/100 women/year. The discrepancy in the figures might be related to the types of IUDs and the duration of use. It is also certainly related to the presence of such infection at the time of insertion. On the same line, the findings are consistent with the study conducted by Sharief $(\mathbf{1 9 9 8})^{26}$ at Basra Hospital, Iraq, where he found that the risk of developing infection among women using IUD is increased 2-4 times, compared to women not using contraception.

According to the present study findings, about two-fifths of the women had dyspareunia (43.0\%). This is in disagreement 
with Masihi et al., (2006) ${ }^{27}$ who have demonstrated that dyspareunia was present in only $9.4 \%$ of 170 women who came to gynecology clinic in Imam Hospital at Iran. The difference in the rates might be explained by the sensitivity of discussing this issue in conservative communities.

Another important problem related to IUD use is the bleeding problems after IUD insertion. The use of copper IUD increases menstrual flow and cramping, which may be particularly severe in the first months of IUD use (Irvine et al., 1998) ${ }^{28}$. The present study revealed that vaginal bleeding was the most commonly reported complication, as reported by $14.4 \%$ of IUD users, and the most common change in menstrual cycle was increased amount of blood (38.1\%). The finding is in congruence with Hubacher and Grimes (2002) $^{29}$ who found that IUD users reported slightly longer bleeding episodes after initiating the IUD. Similarly, Tolley et al., (2005) ${ }^{30}$ found that the majority of IUD users reported an increase in the duration and intensity of bleeding after initiating IUD. On the same line, Hassan et al., (1999) ${ }^{31}$, in a study of 1,039 Egyptian women in seven university hospitals, found that $65.0 \%$ of IUD users were anemic, denoting increased blood loss. These findings were explained by Singh and Al-Amari $(\mathbf{2 0 0 0})^{32}$ by the disturbing effect of IUD on the blood vessels or through altering the clotting mechanism in the lining of the uterus.

The second aim of the present study was to assess to what extent the intervention plan, with and without prophylactic antibiotics, affects the IUD performance. The two intervention subgroups were closely similar in their socio-demographic characteristics, with no statistically significant differences between them. They had also similar parity.

Comparison of the clinical local examination findings revealed no statistically significant differences among women in the two intervention subgroups, either preprogram or at follow-up (FU). The majority had normal vulva and cervix. However, subgroup A women, with no prophylactic antibiotic, had a 
statistically significantly higher incidence of erythema and vaginal discharge at the followup examination, compared to pre-program rate. Also, comparison of the laboratory findings in the two intervention subgroups has shown that women in subgroup $A$ had a statistically significantly higher incidence of bacterial vaginosis, compared to those in subgroup $B$ at the follow-up. Moreover, the percentages of women with positive chlamydial infection in subgroup B dropped from about one-third at the pre-program exam to one-tenth at the follow-up, and the rates of other bacterial infections showed similar decreases from pre-program to follow-up, and these differences were statistically significant. Therefore, erythema and vaginal discharge, as well bacterial vaginosis tended to increase with the lack of prophylactic antibiotic (subgroup A), whereas the use of prophylactic antibiotic in subgroup B women protected them from chlamydial and bacterial infections.

These present study findings are incongruent with those of Grimes and Schulz $(\mathbf{2 0 0 2})^{33}$ who reported no statistically significant differences in the incidence of PID whether women were pre-treated with doxycycline $200 \mathrm{mg}$, azithromycin $500 \mathrm{mg}$, or placebo. The discrepancy with the present study might be related to application of strict rules of selection of proper candidates, as well as the application of infection control measures. In this regard, Walsh et al., (1998) ${ }^{7}$ have stressed that in appropriately screened candidates, the risk of RTls is negligible after IUD insertion, regardless of whether prophylactic antibiotics were given or not.

While much has been written about the clinical aspects of IUD use and discontinuation, less is known about the reasons why use is so low in some countries (Gyapong et al., 2003) ${ }^{9}$. One of these reasons assumed in the present study was the lack of proper information, and the abundance of misconceptions related to use of IUDs. This assumption was confirmed by results of the present study, which showed poor knowledge among women in both intervention groups 
before receiving the program. However, IUDs available to them and the importance of statistically significant improvements in regular follow-up visits.

knowledge were revealed in all areas at the post-test, which were also retained at the FU test. Therefore, the intervention plan was successful in improving women's knowledge about IUD, which is in agreement with Soliman $(1999)^{34}$ who has similarly reported statistically significant differences in the knowledge of the study group after counseling, and their knowledge was retained during the follow-up period.

Also in agreement with these present study findings, Forrest (1996) ${ }^{35}$, in a survey of U.S. women found that respondents knew much less about the IUD, but many perceived it to be unsafe. After having read a description of the method, $46 \%$ expressed an interest in using it. Additionally, the Medical and Service Delivery Guidelines, IPPF (2002) ${ }^{36}$ have emphasized that it is critical that women receive appropriate counseling both before and after IUD insertion, and be informed about the risks associated with IUD use, the type of cause infertility. However, statistically significant improvements were noticed both at the post and follow-up phases. The findings are in congruence with the report of the WHO $(\mathbf{2 0 0 4})^{2}$ about myth that IUDs cause infertility. This fear was attributed to the problems associated with the use of the Dalkon shield, an early IUD that has not been manufactured or distributed for 20 years. On the same line, Gyapong et al., (2003) $)^{9}$ and Brambila and Taracena $(2003)^{8}$ have reported that IUDs were blamed for causing marital disharmony 
and abortion. Women were worried that IUDs could fail, cause heavy bleeding, get lost inside the body, or stick to the unborn child (Katz et al., 2002) $)^{37}$. These authors have clarified that one reason for the rumors and misconceptions was that the public has little factual information. Thus, actual cases that are exaggerated can be a principal source of frightening rumors and myths. Therefore, Timothy and Canavan (1998) ${ }^{20}$ have emphasized that a well-informed patient is more likely to continue with the IUD method and less likely to request premature removal.

\section{CONCLUSION AND RECOMMENDATIONS}

The study revealed that bleeding, infection, and dyspareunia were the most commonly reported problems among IUD users. Women had poor knowledge and many misconceptions about IUDs. The planned nursing intervention succeeded in improving their knowledge and correcting their misconceptions. Prophylactic antibiotics were also effective in reducing infections. Therefore, it is recommended to apply this intervention on a wider scale. To be able to do this, nurses working in family planning clinic need to have updated information about IUDs through periodic and continuous in-service training programs. Also, any woman anticipating an IUD fitting and showing clinical signs of genital infection should be referred for further investigation before the IUD fitting. 
Table 1: Socio-demographic characteristics of women in the assessment survey sample $(n=409)$

\begin{tabular}{|c|c|c|}
\hline Socio-demographic characteristics & No. & $\%$ \\
\hline Age in years (mean $\pm S D)$ & \multicolumn{2}{|c|}{$31.0 \pm 7.5$} \\
\hline Educational level: & & \\
\hline Illiterate & 164 & 40.1 \\
\hline Read/write & 39 & 9.5 \\
\hline Primary/preparatory & 54 & 13.2 \\
\hline Secondary & 108 & 26.4 \\
\hline University & 44 & 10.8 \\
\hline \multicolumn{3}{|l|}{ Occupation: } \\
\hline Housewife & 343 & 83.9 \\
\hline Working & 66 & 16.1 \\
\hline \multicolumn{3}{|l|}{ Residence: } \\
\hline Rural & 305 & 74.6 \\
\hline Urban & 104 & 25.4 \\
\hline \multicolumn{3}{|l|}{ Religion: } \\
\hline Muslim & 389 & 95.1 \\
\hline Christian & 20 & 4.9 \\
\hline Age at marriage (mean $\pm S D)$ & \multicolumn{2}{|c|}{$19.0 \pm 3.6$} \\
\hline Marriage duration in years (mean $\pm S D$ ) & & \\
\hline
\end{tabular}

Table 2: Obstetric data related to contraception among women in the assessment survey sample $(n=409)$

\begin{tabular}{|l|c|c|}
\hline & No. & \% \\
\hline Parity & \multicolumn{2}{|c|}{$4.0 \pm 2.5$} \\
\hline Previous contraceptive use & 278 & 68.0 \\
Previous IUDs use & 159 & 38.9 \\
Complications while using:@ & 72 & 17.6 \\
$\quad$ None & 59 & 14.4 \\
Vaginal bleeding & 43 & 10.5 \\
Infection & 21 & 5.1 \\
Pregnancy & 16 & 3.9 \\
Expulsion of IUDs & 5 & 1.2 \\
Pallor & 62 & 15.2 \\
Others & & \\
Changes in menstrual cycle: @ & 156 & 38.1 \\
Increased amount & 139 & 34.0 \\
Increased duration & 72 & 17.6 \\
Changed cycle length & 57 & 13.9 \\
Amenorrhea & 24 & 5.9 \\
Spotting & 176 & 43.0 \\
\hline Dyspareunia & 89 & 21.8 \\
Contact bleeding following intercourse & & \\
\hline Infections: & 27 & 20.6 \\
Chlamydial infection & 7 & 5.3 \\
Bacterial vaginosis & 32 & 24.4 \\
\hline Other bacterial infection & & \\
\hline
\end{tabular}

(@) Not mutually exclusive

Table 3: Socio-demographic characteristics of women in the two intervention subgroups 


\begin{tabular}{|c|c|c|c|c|c|c|}
\hline \multirow{4}{*}{ Socio-demographic characteristics } & \multicolumn{4}{|c|}{ Intervention group } & \multirow{4}{*}{$x^{2}$} & \multirow{4}{*}{$p$-value } \\
\hline & \multirow{2}{*}{\multicolumn{2}{|c|}{$\begin{array}{c}\begin{array}{c}\text { Subgroup A } \\
\text { (no antibiotic) }\end{array} \\
(n=50)\end{array}$}} & \multirow{2}{*}{\multicolumn{2}{|c|}{$\begin{array}{c}\text { Subgroup B } \\
\text { (antibiotic) } \\
(n=50)\end{array}$}} & & \\
\hline & & & & & & \\
\hline & No. & $\%$ & No. & $\%$ & & \\
\hline Age in years (mean $\pm S D)$ & \multicolumn{2}{|c|}{$28.5 \pm 8.4$} & \multicolumn{2}{|c|}{$31.3 \pm 7.8$} & $t=1.73$ & 0.09 \\
\hline Educational level: & & & & & & \\
\hline Illiterate & 15 & 30.0 & 12 & 24.0 & & \\
\hline Read/write & 5 & 10.0 & 3 & 6.0 & & \\
\hline Primary/preparatory & 6 & 12.0 & 5 & 10.0 & 3.60 & 0.46 \\
\hline Secondary & 15 & 30.0 & 24 & 48.0 & & \\
\hline University & 9 & 18.0 & 6 & 12.0 & & \\
\hline \multicolumn{7}{|l|}{ Occupation: } \\
\hline Housewife & 33 & 66.0 & 32 & 64.0 & & \\
\hline Working & 17 & 34.0 & 18 & 36.0 & 0.04 & 0.83 \\
\hline \multicolumn{7}{|l|}{ Residence: } \\
\hline Rural & 22 & 44.0 & 27 & 54.0 & & \\
\hline Urban & 28 & 56.0 & 23 & 46.0 & 1.00 & 0.32 \\
\hline \multicolumn{7}{|l|}{ Religion: } \\
\hline Muslim & 49 & 98.0 & 47 & 94.0 & & \\
\hline Christian & 1 & 2.0 & 3 & 6.0 & Fisher & 0.62 \\
\hline Age at marriage $($ mean $\pm S D)$ & \multicolumn{2}{|c|}{$20.2 \pm 3.7$} & \multicolumn{2}{|c|}{$20.2 \pm 3.6$} & $t=0.00$ & 1.00 \\
\hline Marriage duration in years (mean $\pm S D$ ) & \multicolumn{2}{|c|}{$8.4 \pm 7.8$} & \multicolumn{2}{|c|}{$11.1 \pm 8.1$} & $t=1.70$ & 0.09 \\
\hline
\end{tabular}

Table 4: Comparison of pre-program obstetric data related to contraception among women in the two intervention subgroups

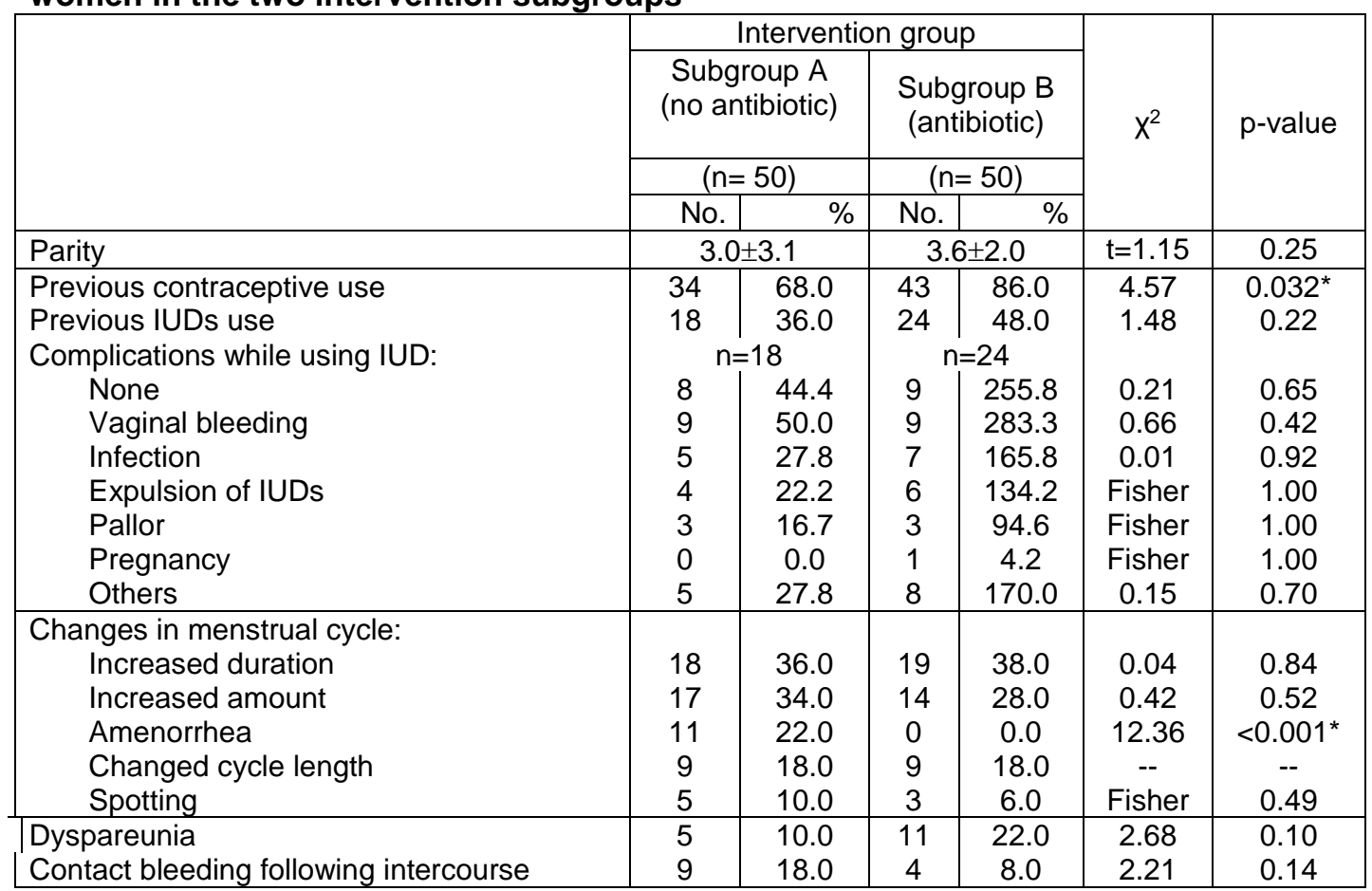

\section{$\left({ }^{*}\right)$ Statistically significant}


Table 5: Comparison of pre-program and follow-up (FU) local clinical examination findings among women in the two intervention subgroups

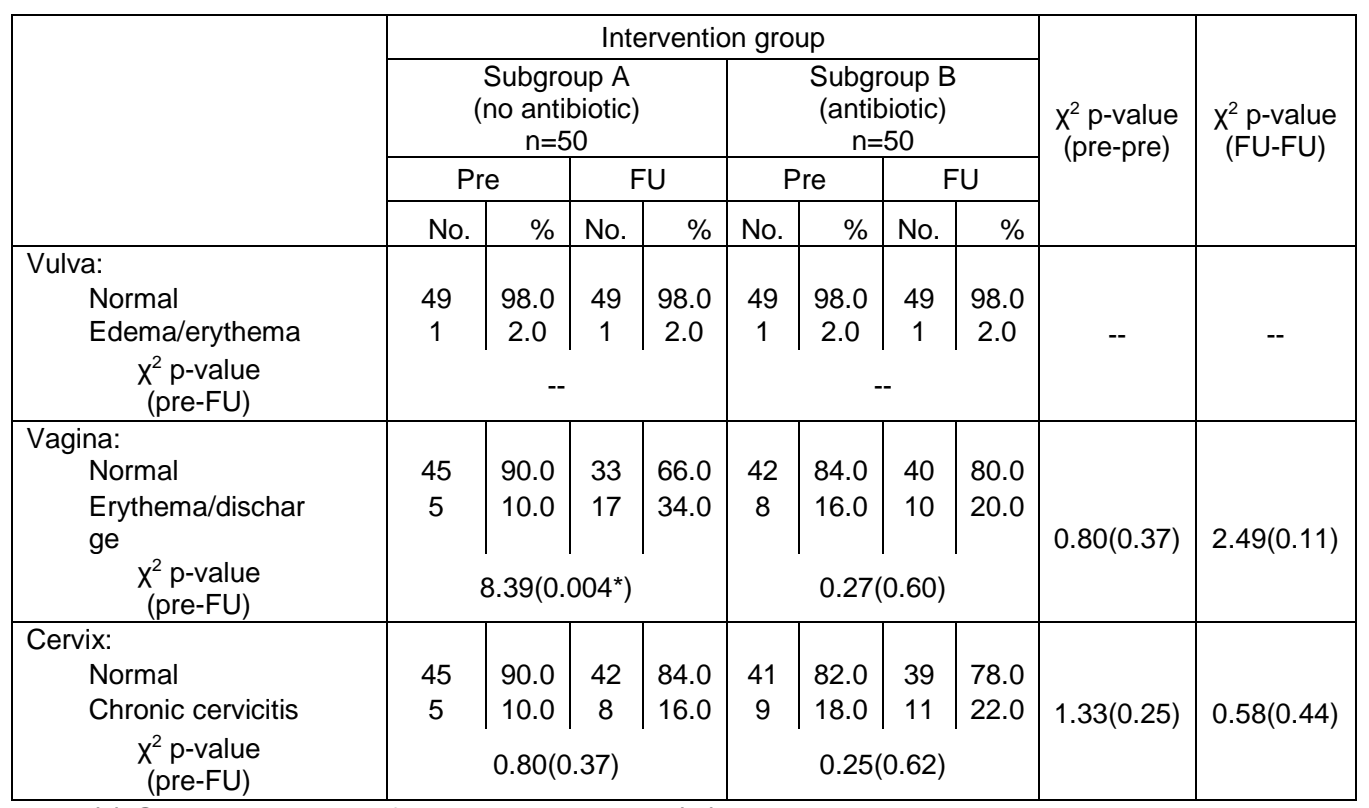

$\left(^{*}\right)$ Statistically significant

(-) Test result not valid

Table 6: Comparison of pre-program and follow-up (FU) laboratory findings among women in the two intervention subgroups

\begin{tabular}{|c|c|c|c|c|c|c|c|c|c|c|}
\hline & \multicolumn{8}{|c|}{ Intervention group } & \multirow{4}{*}{$\begin{array}{c}\mathrm{X}^{2} \\
\mathrm{p}-\mathrm{value} \\
\text { (pre-pre) }\end{array}$} & \multirow{4}{*}{$\begin{array}{c}x^{2} \\
\text { p-value } \\
\text { (FU-FU) }\end{array}$} \\
\hline & \multicolumn{4}{|c|}{$\begin{array}{c}\text { Subgroup A } \\
\text { (no antibiotic) } \\
n=50\end{array}$} & \multicolumn{4}{|c|}{$\begin{array}{c}\text { Subgroup B } \\
\text { (antibiotic) } \\
n=50\end{array}$} & & \\
\hline & \multicolumn{2}{|c|}{ Pre } & \multicolumn{2}{|c|}{ FU } & \multicolumn{2}{|c|}{ Pre } & \multicolumn{2}{|c|}{$\mathrm{FU}$} & & \\
\hline & No. & $\%$ & No. & $\%$ & No. & $\%$ & No. & $\%$ & & \\
\hline Chlamydial infection: & & & & & & & & & & \\
\hline Positive & 16 & 32.0 & 12 & 24.0 & 17 & 34.0 & 6 & 12.0 & & \\
\hline Negative & 34 & 68.0 & 38 & 76.0 & 33 & 66.0 & 44 & 88.0 & $0.05(0.83)$ & $2.44(0.12)$ \\
\hline $\begin{array}{c}X^{2} p \text {-value } \\
\text { (pre-FU) }\end{array}$ & \multicolumn{4}{|c|}{$0.79(0.37)$} & \multicolumn{4}{|c|}{$6.83\left(<0.001^{\star}\right)$} & & \\
\hline \multicolumn{11}{|l|}{ Bacterial vaginosis: } \\
\hline Positive & 8 & 16.0 & 8 & 16.0 & 4 & 8.0 & 2 & 4.0 & & \\
\hline Negative & 42 & 84.0 & 42 & 84.0 & 46 & 92.0 & 48 & 96.0 & $1.52(0.22)$ & $4.00\left(0.046^{\star}\right)$ \\
\hline $\begin{array}{c}X^{2} p \text {-value } \\
\text { (pre-FU) }\end{array}$ & \multicolumn{4}{|c|}{-- } & \multicolumn{4}{|c|}{ Fisher $(0.68)$} & & \\
\hline Other bacterial infection: & & & & & & & & & & \\
\hline Positive & 8 & 16.0 & 9 & 18.0 & 14 & 28.0 & 6 & 12.0 & & \\
\hline Negative & 42 & 84.0 & 41 & 82.0 & 36 & 72.0 & 44 & 88.0 & $2.10(0.15)$ & $0.71(0.40)$ \\
\hline $\begin{array}{c}\mathrm{X}^{2} \mathrm{p} \text {-value } \\
\text { (pre-FU) }\end{array}$ & \multicolumn{4}{|c|}{$0.07(0.79)$} & \multicolumn{4}{|c|}{$4.00\left(0.046^{\star}\right)$} & & \\
\hline
\end{tabular}

$\left(^{*}\right)$ Statistically significant

(--) Test result not valid 
Table 7: Comparison of knowledge related to IUDs among women in the intervention group throughout program phases

\begin{tabular}{|c|c|c|c|c|c|}
\hline \multirow{3}{*}{ Knowledge areas } & \multirow{2}{*}{\multicolumn{3}{|c|}{$\begin{array}{l}\text { Intervention group } \\
(\mathrm{n}=100)\end{array}$}} & \multirow{3}{*}{$\begin{array}{l}x^{2} p \text {-value } \\
\text { (pre-post) }\end{array}$} & \multirow{3}{*}{$\begin{array}{l}X^{2} p \text {-value } \\
\text { (pre-FU) }\end{array}$} \\
\hline & & & & & \\
\hline & Pre & Post & $\mathrm{FU}$ & & \\
\hline External genital organs & 9.0 & 71.0 & 63.0 & $80.08\left(<0.001^{*}\right)$ & $62.28\left(<0.001^{*}\right)$ \\
\hline Internal genital organs & 33.0 & 91.0 & 84.0 & $71.39\left(<0.001^{\star}\right)$ & $53.57\left(<0.001^{\star}\right)$ \\
\hline \multicolumn{6}{|l|}{ IUD: } \\
\hline Shape & 41.0 & 98.0 & 93.0 & $76.64\left(<0.001^{\star}\right)$ & $61.15\left(<0.001^{*}\right)$ \\
\hline Site of insertion & 78.0 & 93.0 & 91.0 & $9.07\left(0.003^{\star}\right)$ & $6.45\left(<0.001^{\star}\right)$ \\
\hline Mechanism of action & 31.0 & 94.0 & 92.0 & $84.67\left(<0.001^{\star}\right)$ & $78.58\left(<0.001^{\star}\right)$ \\
\hline $\begin{array}{l}\text { Who is responsible for } \\
\text { insertion }\end{array}$ & 84.0 & 100.0 & 100.0 & $17.39\left(<0.001^{\star}\right)$ & $17.39\left(<0.001^{\star}\right)$ \\
\hline Effectiveness & 58.0 & 96.0 & 97.0 & $40.77\left(<0.001^{\star}\right)$ & $43.61\left(<0.001^{\star}\right)$ \\
\hline Suitable time for insertion & 15.0 & 62.0 & 46.0 & $46.65\left(<0.001^{\star}\right)$ & $22.67\left(<0.001^{\star}\right)$ \\
\hline $\begin{array}{l}\text { Schedule of visits and follow- } \\
\text { up }\end{array}$ & 52.0 & 98.0 & 97.0 & $80.08\left(<0.001^{\star}\right)$ & $80.08\left(<0.001^{\star}\right)$ \\
\hline Indications & 43.0 & 98.0 & 96.0 & $80.08\left(<0.001^{\star}\right)$ & $80.08\left(<0.001^{*}\right)$ \\
\hline Contraindications & 38.0 & 96.0 & 93.0 & $80.08\left(<0.001^{\star}\right)$ & $80.08\left(<0.001^{\star}\right)$ \\
\hline Advantages & 51.0 & 97.0 & 94.0 & $80.08\left(<0.001^{\star}\right)$ & $80.08\left(<0.001^{\star}\right)$ \\
\hline Disadvantages & 56.0 & 92.0 & 95.0 & $33.68\left(<0.001^{\star}\right)$ & $41.11\left(<0.001^{\star}\right)$ \\
\hline Ideal method to care & 2.0 & 91.0 & 90.0 & $159.20\left(<0.001^{\star}\right)$ & $155.88\left(<0.001^{*}\right)$ \\
\hline Times of checking strings & 51.0 & 97.0 & 98.0 & $54.99\left(<0.001^{\star}\right)$ & $58.14\left(<0.001^{\star}\right)$ \\
\hline $\begin{array}{l}\text { When a copper IUD need to } \\
\text { be replaced }\end{array}$ & 71.0 & 100.0 & 100.0 & $33.92\left(<0.001^{*}\right)$ & $33.92\left(<0.001^{*}\right)$ \\
\hline Warning signs & 66.0 & 96.0 & 99.0 & $29.24\left(<0.001^{*}\right)$ & $37.71\left(<0.001^{\star}\right)$ \\
\hline
\end{tabular}

$\left(^{*}\right)$ Statistically significant 
Table 8: Comparison of misconceptions related to IUDs among women in the intervention group throughout program phases

\begin{tabular}{|c|c|c|c|c|c|}
\hline \multirow{3}{*}{ Misconceptions about IUD } & \multicolumn{3}{|c|}{$\begin{array}{l}\text { Intervention group } \\
\qquad(\mathrm{n}=100)\end{array}$} & \multirow{3}{*}{$\begin{array}{l}X^{2} p \text {-value } \\
\text { (pre-post) }\end{array}$} & \multirow{3}{*}{$\begin{array}{l}X^{2} p \text {-value } \\
\text { (pre-FU) }\end{array}$} \\
\hline & \multicolumn{3}{|c|}{$\%$ correct concept } & & \\
\hline & Pre & Post & FU & & \\
\hline $\begin{array}{l}\text { IUD can travel from uterus to other } \\
\text { parts of the body such as heart or } \\
\text { brain }\end{array}$ & 37.0 & 2.0 & 2.0 & $39.02\left(<0.001^{*}\right)$ & $39.02\left(<0.001^{*}\right)$ \\
\hline $\begin{array}{l}\text { IUD can enter in baby's brain or body } \\
\text { in case of pregnancy }\end{array}$ & 30.0 & 1.0 & 3.0 & $32.11\left(<0.001^{\star}\right)$ & $26.46\left(<0.001^{\star}\right)$ \\
\hline $\begin{array}{l}\text { IUD will prevent women from having } \\
\text { babies after it is removed }\end{array}$ & 22.0 & 7.0 & 6.0 & $9.07\left(0.003^{\star}\right)$ & $10.63\left(0.001^{\star}\right)$ \\
\hline $\begin{array}{l}\text { Women should have a rest period after } \\
\text { using IUD for several years or after its } \\
\text { recommended removal }\end{array}$ & 45.0 & 12.0 & 9.0 & $26.72\left(<0.001^{\star}\right)$ & $32.88\left(<0.001^{*}\right)$ \\
\hline $\begin{array}{l}\text { IUD can cause severe bleeding and } \\
\text { affect health }\end{array}$ & 72.0 & 30.0 & 31.0 & $35.29\left(<0.001^{\star}\right)$ & $33.65\left(<0.001^{*}\right)$ \\
\hline IUD can affect coitus & 41.0 & 4.0 & 6.0 & $39.25\left(<0.001^{*}\right)$ & $34.07\left(<0.001^{*}\right)$ \\
\hline IUD can affect sexual desire & 47.0 & 10.0 & 6.0 & $33.59\left(<0.001^{*}\right)$ & $43.15\left(<0.001^{*}\right)$ \\
\hline
\end{tabular}

$\left(^{*}\right)$ Statistically significant 


\section{REFERENCES}

1. Gareen IF. Center for Statistical Sciences and the Department of Community Health, Box G-H, Brown University School of Medicine, Providence, RI, 02912, USACurrent Women's Health Reports. 2003;3:280287. In: Harris JRW, Forster SM, eds. Recent advances in sexually transmitted diseases and AIDS. No 4. London: Churchill Livingstone, 1991:219- 262.

2. 2-WHO. Improving access to quality care in family planning: Medical eligibility criteria for contraceptive use. Third edition. Geneva: WHO; 2004.

3. Shaaban MM. Gynecology for postgraduates, theory and practice; Contraception and Family planning; Genital tract infections; Vol. I \&ll pages; 300-371 \& 913-936. Assiut University, Assiut, Egypt; 2002.

4. Kaunitz MA. Intrauterine devices: Safe, effective, and underutilized. With new devices and better knowledge, the risk of infection is low. Women Health Primary Care. 1999;2(1):39-47.

5. MMWR. 2002: Sexually transmitted diseases. Guidelines. 2002;51 (RR-6): 48-52.

6. Barnett B. Copper T IUD: safe, effective, reversible, lack of accurate information and other barriers discourage IUD use. Network. 2000;20(1) reproductive health.

7. Walsh T, Grimes D, Frezieres R, et al. Randomized controlled trial of prophylactic antibiotics before insertion of intrauterine devices. Lancet. 1998;1005-09.
8. Brambila C, Taracena B. Availability and acceptability of IUDs in Guatemala," Frontiers final report. Washington, DC: Population Council; 2003.

9. Gyapong J, Addico G, Osei I, Abbey M, Kobinah DA, Agyarko $\mathrm{HO}$, et al. An assessment of trends in the use of the IUD in Ghana, FRONTIERS Final Report. Washington, D.C.: Population Council; 2003

10. David GA. Intrauterine device and upper-genital-tract infection. Lancet. 2000; 356(9234): 1013.

11. Steiner MJ. Contraceptive effectiveness: what should the counseling message be? JAMA. 1999; 282:1405.

12. Finger RW. Copper T IUD: Safe, effective, reversible lack of accurate information and other barriers discourage IUD use. Network. 2002; 20 (1): 4-11.

13. Harikarnpukdee D, Sirimai K, Kiriwat $O$, Boriboonhirunsarn D. Prevalence of bacterial vaginosis among intrauterine device users in Thai women attending family planning clinic, Siriraj Hospital. J Med Assoc Thai. 2004;87 Suppl. 3

14. Grimes DA. Intrauterine device and upper-genital-tract infection. Lancet. 2000;356(9234): 1013.

15. Coffield AB, Maciosek MV, McGinnis $\mathrm{JM}$, et al. Priorities among recommended clinical preventive services. Am J Prev Med. 2001;21:1-9.

16. Teran S, Walsh C, Irwin KL. Chlamydia trachomatis infection in women: bad news, good news, and next steps in prevention. J Am Med Women Assoc. 2001;56:100-104.

17. Walsh $\mathrm{CM}$, Irwin $\mathrm{KL}$. Combating the silent Chlamydia epidemic. 
Contemporary OB/GYN® Archive April 1 2002.

18. Grimes DA, Schulz KF. Antibiotic prophylaxis for intrauterine contraceptive device insertion. The Cochrane Libary (Issue 3). Oxford: Update Software; 2002.

19. Population Information Program. Principles and practice of clinical gynecology. 2d ed. New York: Churchill Publishing Group; Volume XXIII. 1996. Number, pp. 112-116.

20. Timothy $\mathrm{P}$, Canavan MD, Appropriate use of the intrauterine device, Lancaster General Hospital, American Academy of Family physicians, December, Today. Proceedings of the 4th Congress of the European Society of Contraception. 1998.

21. WHO. Intrauterine devices. Technical and managerial guidelines for services. Geneva: WHO; 1997.

22. Hubacher D, Reyes V, Lillo S, Pierre-Louis B, Zepeda A, Chen PL, et al. Preventing copper intrauterine device removals due to side effects among first-time users: randomized trial to study the effect of prophylactic ibuprofen; Hum. Reprod. Advance Access published online on February 16, 2006 Published by Oxford University Press.

23. Faúndes HA, Telles E, Cristofoletti $M$, Faúndes $D$, Castro $S$. The risk of inadvertent intrauterine device insertion in women carriers of endocervical Chlamydia trachomatis; Departamento de Ginecologia e Obstetrícia, Faculdade de Ciências Médicas, Universidade Estadual de Campinas (UNICAMP), 13 March revised 26 June 1998.
24. Bogavac M, Milosevic S, PavlovMirkovic M. Intrauterine device and Chlamyadia Trachomatis infection; Department of Obstetrics and Gynaecology. Clinical Centre, Novi Sad, Yugoslavia. FHI; 2004.

25. Avonts $D, \quad$ Sercu $M$, Heyerick $P$, Vandermeeren I, Meheus A, Piot P. Incidence of uncomplicated genital infections in women using oral Contraception or an intrauterine device: a prospective study. Sex Transm Dis. 2005;17(1):23-9.

26. Sharief M. 1998: Genital infections among women using various contraceptive methods in Basra, Iraq. Eastern Mediterranean Health Journal. 1998;4(3): 487-92

27. -Masihi S, Barati M, Moremazi F. Dyspareunia: A neglected problem. The first World Congress on Gender-specific Medicine, 23-26 February 2006, Berlin, Germany

28. Irvine GA, Campbell-Brown MB, Lums-den MA, et al. Randomized comparative trial of the levonorgestrel intrauterine system and norethisterone for treatment of idiopathic menorrhagia. Br J Obstet Gynaecol. 1998;105:592-8.

29. Hubacher D, Grimes DA. Noncontraceptive health benefits of intrauterine devices: A systematic review. Obstetrical and Gynecological Survey. 2002;57(2):120-8.

30. Tolley E, Loza S, Kafafi L, Cummings S. The impact of menstrual side effects on contraceptive discontinuation: Findings from a longitudinal study in Cairo, Egypt. 
International Family Planning Perspectives. 2005;31(1) March.

31. Hassan EO, El-Hussinie M, El-Nahal N. The prevalence of anemia among clients of family planning clinics in Egypt. Contraception. 1999;60(2): 93-9.

32. Singh R, Al-Amari M. Clinical performance of intrauterine device $\mathrm{TCu}$ 380 A. In: Sivin I, Greenslade F, Schmidt F, Waldman SN. The copper T 380. 2000; 6(5/6):1073-82.

33. Grimes DA, Schulz KF. Antibiotic prophylaxis for intrauterine contraceptive device insertion (Cochrane Review). In: The Cochrane Library, 4. Oxford: Update Software; 2000.
34. Soliman $\mathrm{MH}$. Impact of antenatal counseling on couples' knowledge and practice of contraception in Mansoura, Egypt. Eastern Mediterranean Health Journal. 1999;5(5):1002-13.

35. Forrest JD. U.S. women's perception of and attitudes about the IUDs. Obstetrical and Gynecological Survey. 1996;51(12): 17S.

36. Medical and Service Delivery Guidelines, IPPF Medical Department. Cumulative sales of IUDs through PSI projects reached. 2002; 906,808.

37. Katz RK, Johnson LM, Janowitz B, Carranz JM. Reasons for the Low Level of IUD Use in El Salvador. International Family Planning Perspectives. 2002;28(1): 